\title{
Social Class and Party Identification During the Clinton, Bush, and Obama Presidencies
}

\author{
Stephen L. Morgan, Jiwon Lee
}

Johns Hopkins University

Abstract: Through an analysis of the 1994 through 2016 General Social Surveys, this article demonstrates that a substantial proportion of eligible voters within the working class turned away from solid identification with either the Democratic Party or the Republican Party during the Obama presidency. Even before the 2016 election cycle commenced, conditions were uncharacteristically propitious for a Republican candidate who could appeal to prospective voters in the working class, especially those who had not voted in recent presidential elections but could be mobilized to vote. These findings support the contested position that variation in party identification is a genuine leading indicator of electoral outcomes and perhaps also, in this case, of party realignment.

Keywords: social class; party identification; voting; class politics; dealignment

Citation: Morgan, Stephen L., and Jiwon Lee. 2017. "Social Class and Party Identification During the Clinton, Bush, and Obama Presidencies." Sociological Science 4: 394-423.

Received: June 12, 2017

Accepted: June 25, 2017

Published: August 3, 2017

Editor(s): Jesper Sørensen, Sarah Soule

DOI: $10.15195 / \mathrm{v} 4 . \mathrm{a} 16$

Copyright: (C) 2017 The Author(s). This open-access article has been published under a Creative Commons Attribution License, which allows unrestricted use, distribution and reproduction, in any form, as long as the original author and source have been credited. (C) (i)
$\mathrm{D}$ URING the 2016 primary and general election campaigns for US president, conjectures about the preferences of working-class voters were offered to explain the puzzling early successes of Bernie Sanders and Donald Trump. Following the election of Donald Trump to the presidency, many pollsters, journalists, and opinion leaders attributed his surprising victory over Hillary Clinton in the "blue wall" swing states of Michigan, Pennsylvania, and Wisconsin to working-class voters, whose allegiance to the Democratic Party they argued must have been weaker than anticipated. Journalistic analysis of exit poll data suggested that voters with lower levels of education were more likely to vote Republican in 2016 than in prior years, and this pattern is often cited as support for the shifting loyalties of the working class.

In this article, through analysis of the 1994 through 2016 General Social Surveys (GSSs), we consider the relationship between class position and party identification during the last three two-term presidencies of Bill Clinton, George Bush, and Barack Obama. The 2016 GSS was planned for and fielded during the spring, summer, and fall of 2016, and as a result the 2016 presidential vote was not measured (although it will be, retrospectively, for the 2018 GSS). Accordingly, although we cannot (yet) model voting choices for Donald Trump relative to Hillary Clinton and other candidates using the GSS data, we can at this point model how party identification evolved over the prior 24 years as well as where it stood in the months prior to the 2016 general election. Perhaps most importantly, unlike every other data source known to us, the GSS now enables consistent and precise measurement of both social class and party identification over all three presidencies. ${ }^{1}$

In the remainder of this introductory section, we offer brief characterizations of the background literature on class position, party identification, and voting in order to connect the current public discussion of the preferences of working-class voters 
to the sustained scholarship that has accumulated on these relationships since the 1940s. This literature, in both sociology and political science, offers crucial guidance for how to study trajectories of party identification as well as class-related party alignments. Some of this literature is out of fashion in current debates, and we introduce it to uninitiated readers because of its inherent value for understanding the most recent trends in party preferences and voting decisions.

\section{Class Voting in the United States and in Comparative Perspective}

The most important piece of sociological scholarship on the political preferences of alternative social classes in the United States is the 1999 book, Social Cleavages and Political Change: Voter Alignments and US Party Coalitions, by Manza and Brooks. ${ }^{2}$ Their research was undertaken amidst debate within comparative political sociology on whether traditional left-right class voting was in decline, following from the contested hypothesis that class had become a less prominent basis for political division in increasingly affluent—and supposedly more egalitarian-postindustrial societies. ${ }^{3}$ Supplemented by comparative work (e.g., Nieuwbeerta, de Graaf, and Ultee 2000) and work with complementary data sources on US voters (e.g., Weakliem 1997), the analysis that Manza and Brooks (1999) undertook using presidential voting data from the American National Election Studies (ANES) has contributed to a near consensus on the empirics in question.

First, left-right class voting in the United States has always been more complicated than in many other countries, in part because of racial and regional differences but also because of the constraints of an electoral system that is more easily dominated by only two parties. Second, between the 1950s and the early 1990s, the party alignment of alternative social classes evolved because many professionals and other highly educated voters moved away from the Republican Party toward the Democratic Party. ${ }^{4}$ This shift, however, is not itself easily separable from a simultaneous shift among whites in southern states away from the Democratic Party to the Republican Party, which is usually interpreted as a reaction to the Democratic Party's support of the civil rights movement. Third, once these complexities are recognized, and models are fit that attempt to adjust for them, the gross predictive power of class has declined less than was argued by proponents of the declineof-class thesis. The crux of the Manza and Brooks argument is that parties have evolved, and new voting coalitions have emerged in response to their strategies, but class itself has remained an important predictor of the choices of voters.

Since the 1990s, research on these questions has slowed, partly as a natural response to the pitched disagreements of the 1990s and partly because of recognition that a variety of new cross-cutting pressures have emerged, which have begun to interact in dynamic fashion with party strategy. With the growth of labor market inequality coming into full view by the end of the 1990s, a key presupposition of the decline-in-class-voting hypothesis-that the relative equality of increasingly affluent postindustrial societies would tamp down between-class economic interests-was judged false. And, with the emergence of a new literature on polarization, along 
with sophisticated arguments about the sorting of US voters across parties, concern with the evolving preferences of social classes waned. The latter development was not entirely unforeseen by combatants in the class voting debates, with, for example, Goldthorpe (1999) noting in a postscript to his analysis of the 1964 through 1992 British elections that the centrist move of the Labour Party in the general election of 1997 had weakened traditional left-right class voting in Britain. For analysts of the United States, Bill Clinton's move toward the center in 1992, and then further in 1996, generated similar shifts. Manza and Brooks (1999) concluded that, in addition to increasing the appeal of the Democratic Party to more highly educated voters, especially women, evidence had begun to emerge in the 1996 election that unskilled workers, whose economic standing was under threat, had begun to move away from the Democratic Party as well.

\section{The Central Role of Party Identification in Electoral Outcomes}

The class voting debate just summarized was focused almost entirely on electoral outcomes, measured by retrospective self-reports of votes by sampled respondents to national surveys. To understand the important role that party identification plays in generating electoral outcomes, an older literature developed the guiding frame that continues to structure current research. ${ }^{5}$

The earliest systematic voting studies were launched by sociologists in single communities, and chief among these are the "Columbia studies" of presidential elections among voters in Erie County, Ohio, and Elmira, New York, which were conducted by Lazarsfeld and his colleagues (see Lazarsfeld, Berelson, and Gaudet [1944] 1948 and Berelson, Lazarsfeld, and McPhee [1954] 1986). Instrumental in developing survey analysis as a powerful tool for the social sciences, these studies examined the consequences of group membership and associational interaction for the development of political preferences and voting choices.

Among many other findings, Lazarsfeld and his colleagues demonstrated that social class position in the community shaped presidential vote intention and subsequent vote choice, in part as an expression of economic interests and in part by how it structured social interaction with others. ${ }^{6}$ In addition, they argued that party identification was a type of cognitive attachment that could pull unstable voters back to expected voting patterns, predictable by their personal situations and associational ties. However, because of the measurement strategy that they chose, which did not clearly separate party identification from "proper vote intention" and "former party allegiance," they were unable to place party identification within their structural process model that posited reversion to stable, party-based voting in the presence of cross pressures arising from many sources.

The development of national studies of elections then moved west to the University of Michigan, where the landmark National Election Studies were conducted from 1952 onward (and later renamed the ANES, noted above as the data source analyzed by Manza and Brooks). The publication of The American Voter in 1960 by 
Campbell et al. generated an enduring consensus in political science that understanding party identification is crucial when investigating electoral outcomes. ${ }^{7}$

After offering a panel study similar in design to the Columbia studies but national in scope, Campbell and his colleagues presented sustained evidence for a core argument of their contribution:

In a survey interview most of our citizens freely classify themselves as Republicans or Democrats and indicate that these loyalties have persisted through a number of elections. Few factors are of greater importance for our national elections than the lasting attachment of tens of millions of Americans to one of the parties. These loyalties establish a basic division of electoral strength within which the competition of particular campaigns takes places. And they are an important factor in assuring the stability of the party system itself. (Campbell et al. 1960:121)

They offered a model for voting in the shape of a "funnel of causality," with party identification halfway down to the spout, weighed down by social class and demographic characteristics above it, and pushing on policy issues, campaigns, and candidates beneath it. Inspired by field theory, and borrowing the reference group form of identity theory used also by Lazarsfeld and colleagues, they conceived of party identification as deeply shaped by socialization, stable across elections because of affective commitment, and resistant to change. ${ }^{8}$ As we will discuss below, their key innovation was a new measurement strategy that enabled the separation of party identification from past voting history and intended future voting.

Since the articulation of this explanation, political scientists in the United States have devoted an enormous amount of energy to assessing support for it. ${ }^{9}$ We will discuss some key alternative proposals for the study of party identification below, but first we must present the measure of party identification developed by the Michigan group because it continues to be used in most research on the topic, including for the GSS and in this article.

\section{The ANES Measure of Party Identification}

Among its many contributions, an important legacy of The American Voter (and related studies of the time) is a general two-step set of questions designed to elicit party identification from survey respondents. The first question begins with a "generally speaking" lead-in that is designed to elicit a stable attachment rather than a vote intention or other more immediate political sentiment:

"Generally speaking, do you usually think of yourself as a Republican, Democrat, Independent, or what?"

If the respondent selects Republication or Democrat, they are asked the following:

“Would you call yourself a strong Republican/Democrat or not a very strong Republican/Democrat?" 
If the respondent selects Independent, they are asked the following:

"Do you think of yourself as closer to the Republican or Democratic Party?"

Answers to these three questions permit the construction of an ordinal sevencategory classification, from Strong Republican to Strong Democrat (with studyspecific options for how to handle respondents who offer an alternative party in response to the first question). In practice, the seven categories are usually collapsed to various three-category and five-category variants.

Particular collapsing practices have been debated since the 1960s. After noting how The American Voter privileged the preservation of a broad category of independents, combining leaning Republicans and Democrats with independents who would not admit closeness to one party or the other, Keith et al. (1992) argued in their book The Myth of the Independent Voter that, as a default position, leaners should be categorized with the party toward which they lean. Based on more than a decade of prior research, they argued that leaning independents tend to vote with the party to which they lean, and that claims of independence among leaners often signal openness and responsible citizenship more frequently than either genuinely centrist views or ignorance of political issues. In this article, we will code leaning independents in both ways, but we also demonstrate why utilizing the broad categorization of independents, as in The American Voter, generates more illuminating results when moving past voters to all those who are eligible to vote.

\section{Insurgent Perspectives on Party Identification}

The sharp decline in identification with the Republican Party after the Watergate scandal and Nixon resignation bolstered the case for revisions to the claims from The American Voter that party identification is a stable attachment that is highly resistant to change. For the next 30 years, political scientists debated competing models with considerable intensity, and the core of the debate centered on whether party identification is responsive in the short-run to both political events and perceptions of the effectiveness of politicians who belong to alternative parties (see Fiorina 2002 for a review).

A primary rival of The American Voter position crystallized in the 1980s under the name of macropartisanship (see MacKuen, Erikson, and Stimson 1989; Erikson, MacKuen, and Stimson 2002). For this model, aggregate movements in party identification are a leading indicator of electoral outcomes, especially at the presidential level. At any given point in time, the distribution of party identification is the accumulation of current and recent sentiment, largely shaped by perceptions of the effectiveness of the party already in control, as implicitly set against the out-ofoffice party that might do better. This model built on other "revisionist" proposals, including the argument of Fiorina (1981) that party identification can be thought of as retrospective voting, which has a cognitive basis in assessments of past performance, not merely socialization or attachment. Even further from The American Voter position, micromodels were proposed that characterized voters as Bayesian actors, synthesizing available information and recalibrating party identification in 
real time while forming consistent vote intentions in the run-up to each election (see Achen 1992), possibly using the preferences of their parents as priors (see Achen 2002).

The empirical support for alternative positions in this debate depends on the data source analyzed, with Gallup data favoring macropartisanship more strongly and ANES data favoring emotional attachment more strongly. ${ }^{10}$ The GSS has tended to line up with the evidence from ANES more directly because it uses the "generally speaking" lead-in that was pioneered for the ANES (see Green, Palmquist, and Schickler 2002). The standard Gallup question-“'In politics, as of today, do you consider yourself a Republican, a Democrat, or an Independent?"- appears to move more in the short-run (see Abramson and Ostrom 1991, 1994).

The core debate on the worth of alternative models of party identification seems to have run its course. ${ }^{11}$ And, although no winner was ever declared, nearly all participants would appear to agree that party identification must continue to be measured and incorporated into explanations of electoral outcomes. A consistent, although secondary, theme, which has been driven more by the vicissitudes of elections than internal debates among scholars, is consideration of whether periods of political instability are accompanied by (or possibly preceded by) increases in the proportion of voters who are loyal to neither the Democratic Party nor the Republican Party.

With the outcome of the 2016 presidential election, we appear to be in such a moment again, with interest arising in whether a period of party dealignment may be leading to an emergent party realignment in which successful candidates will reconfigure parties around new bundles of policy positions that can effectively mobilize prospective voters in new coalitions. In this article, we consider whether social class should be considered a dimension that has structured any dealignment in the run-up to the 2016 election. For context, we project our analysis backward to the endpoint of the class voting debates in sociology, the bulk of which concluded with consideration of the reelection of Bill Clinton to the presidency. Accordingly, in the remainder of this article, we offer an analysis of the relationship between social class and party identification from 1994 through 2016.

\section{Data and Measures}

Data are drawn from the 1994 through 2016 General Social Surveys, which, when combined, sampled a total of 33,078 respondents. ${ }^{12}$ For our analytic sample, we first dropped 2,851 respondents who reported that they were less than 25 years old, leaving a sample of 30,227 respondents 25 years and older. Even though most of these younger GSS respondents reported a party identification, we dropped them from analysis for two reasons. First, the GSS, like most other surveys of adults, only samples individuals living at residential addresses. The GSS does not sample those living in group quarters, such as college dormitories, and as a result the coverage of 18- to 24-year-olds is compromised in ways that are not random with respect to either class position or party identification. A common decision to mitigate this problem is to drop from analysis all individuals who are in the age range of modal college students, and age 25 is a common cutoff. Second, in portions of the analysis 
below, we will restrict the sample to eligible voters, measured by whether or not they declared themselves eligible to vote in the last presidential election during their GSS interview. We cannot use this measure for the youngest GSS respondents without confounding ineligibility because of age from ineligibility for other reasons (i.e., citizenship or, in some states, felon status).

Of the 30,227 respondents who did not indicate that they were age 24 or younger, 99.5 percent $(N=30,051)$ had nonmissing data for age, gender, and years of completed education. In addition, 98.7 percent $(N=29,849)$ had nonmissing data for these variables and for party identification. Finally, 95.6 percent $(N=28,855)$ had nonmissing data for these variables and for both party identification and social class. We will use these overlapping analysis samples throughout our study.

Note, however, that the largest component of missing data is systematically determined; these are the individuals who do not have an observed social class because they did not report a current or last occupation (presumably because they were never in the labor force). Unlike with earlier waves of the GSS, from 1994 onward this group of respondents comprises less than five percent of the sample because of the increase in the labor force participation of women. Before introducing social class as a dimension of analysis, we offer results for all eligible voters in the GSS and demonstrate that the aggregate pattern of party identification does not depend on whether these nonclass respondents are included in the analysis. Skeptical readers should skip ahead and compare Figure 1 below to Figures A1-A and A1-B in the online supplement.

\section{Measurement of Party Identification and Social Class}

For this article, we code party identification using responses to a pair of GSS questions (which, as discussed above, were developed for the ANES). The first question is as follows:

"Generally speaking, do you usually think of yourself as a Republican, Democrat, Independent, or what?"

If the respondent selects independent, they receive the follow-up question:

"Do you think of yourself as closer to the Republican or Democratic Party?"13

We offer results based on two four-part classifications for Republicans, Democrats, independents, and others. The two classifications differ based on whether leaning independents are coded as Republicans or Democrats, which can be determined by their response to the follow-up question. The "staunch" independents who profess not to lean one way or the other remain as independents in both classifications.

For social class, we adopt a new coding based on the 2010 US Census Occupation Classification, which is now available for most GSS respondents. The descriptions of the classes are presented in Table 1, and the rationale for the coding is based on the employment relations perspective elaborated in cross-national work on social stratification (e.g., Erikson and Goldthorpe 1992) and, used, with some variation, in the cross-national literature on class voting (see Evans 1999b). Variants of this 
Table 1: EGP class descriptions.

\begin{tabular}{ll}
\hline Label & Description \\
\hline $\mathrm{I}$ & Higher-grade professionals, administrators, managers, and officials \\
$\mathrm{II}$ & Lower-grade professionals, administrators, managers, and officials \\
$\mathrm{IIIa}$ & Routine nonmanual and service employees, higher grade \\
$\mathrm{IIIb}$ & Routine nonmanual and service employees, lower grade \\
$\mathrm{IVab}$ & Nonprofessional self-employed workers \\
$\mathrm{IVc}$ & Owners and managers of agricultural establishments \\
$\mathrm{V}$ & Higher-grade technicians and repairers, public safety workers, performers, \\
& and supervisors of manual workers \\
$\mathrm{VI}$ & Skilled manual workers, lower-grade technicians, installers, and repairers \\
$\mathrm{VIIa}$ & Semiskilled and unskilled manual workers, not in agriculture \\
$\mathrm{VIIl}$ & Agricultural workers and their first-line supervisors and other workers in \\
& primary production \\
Military & All members of the armed forces
\end{tabular}

Notes: For all detailed occupations assigned to each class, see Table A2 of Morgan (2017), which also includes sample counts for each occupation, tabulated for the three four-survey periods considered in this article: 1994-2000, 2002-2008, and 2010-2016.

class schema are usually labeled EGP based on its first motivation and usage in Erikson, Goldthorpe, Portocarero (1979). For details of the specific coding used here, see Morgan (2017), which offers a rationale and process for coding the class structure of the United States using the occupational classification developed by the federal statistical agencies of the US government, as implemented for the 2012-2015 American Community Surveys. We offer example occupations for each class in the text below when reporting results.

\section{Results}

Before considering how class position is related to party identification, we consider overall trends in party identification during the Clinton, Bush, and Obama presidencies. The first panel of Figure 1 presents the proportion of GSS respondents who chose each of four categories: Democrat (in blue), Republican (in red), another party (in gray), or independent (in black). For the first panel, the sample is restricted to all individuals age 25 and older who voted in the last presidential election, and the categorization of party identification codes leaners as either Democrat or Republican so that those who remain as independents are what we refer to as "staunch independents" (and whom other scholars sometimes label "true independents" or "pure independents").

The bar associated with each point on the trend lines is equal to plus or minus one standard error, and as such the bars are conventional 68-percent confidence intervals. In most cases, the GSS sample is large enough that these error bars are 
Voters (Staunch independents)

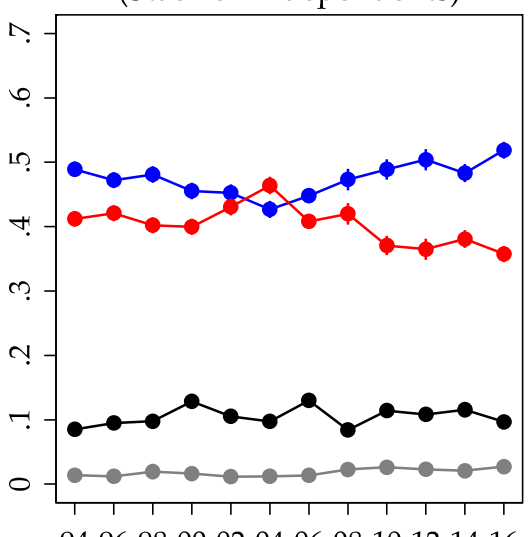

949698000204060810121416
Voters

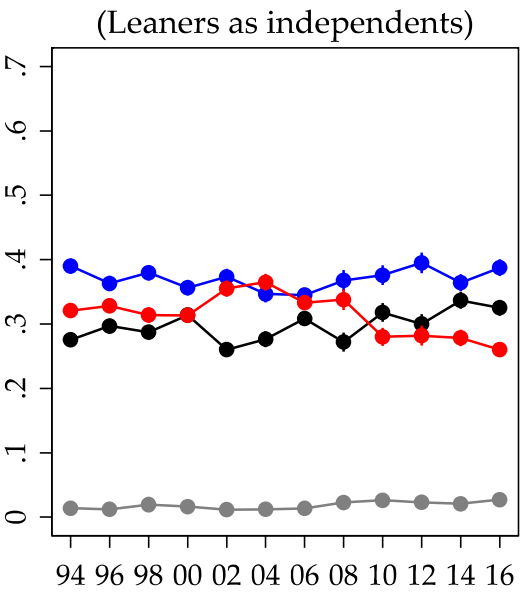

Eligible voters

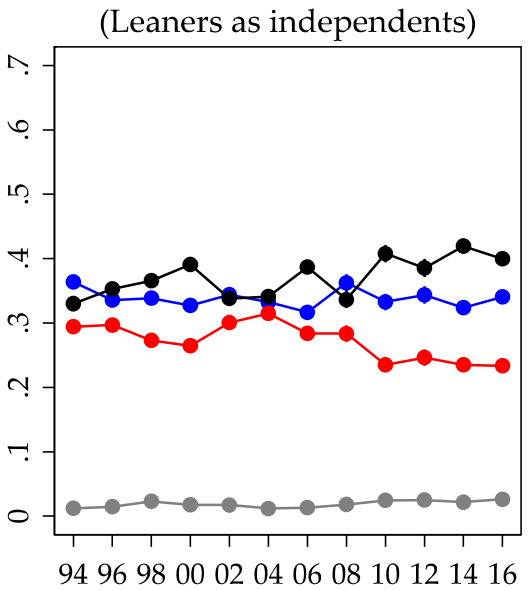

Figure 1: Trends in identification with the Democratic Party (blue), Republican Party (red), another party (gray), and independent (black). Notes: $N=21,053$ for panels 1 and 2, and $N=29,029$ for panel 3 . Adding to the sample GSS respondents who reported that they were ineligible to vote in the last presidential election but reported a current party identification in the interview would boost the $N$ to 29,998 .

smaller than the dots that represent the point estimates, unlike what we will see below when the trend lines are estimated separately by class.

The results of the first panel demonstrate the advantage held by the Democratic party when leaning independents are coded as Democrats or Republicans. Only during the 2004 election year was the proportion of Republicans higher, and, as we will discuss below, this is the one year when the GSS was fielded at the end of the calendar year, so that the majority of its interviews were conducted after the reelection of Bush to the presidency. Thus, a transitory bandwagon effect may have boosted the proportion of Republicans in 2004.

For the second panel of Figure 1, we move independents who lean Democrat or Republican into a broader category that includes all staunch and leaning independents. We do not have any clear characterization of who these leaning individuals are, and there are many competing explanations in the literature. Because the individuals recoded for the second panel are those who claimed to have voted in the last presidential election, it is unlikely that they are low-information nonvoters who chose not to go to the polls because of indifference to the political process. Regardless of their characteristics, the change in the results is clear. The proportion for the trend line in black increases a great deal and appears to be increasing during the Obama presidency, surpassing the proportion of Republicans in 2010 through 2016. The relative advantage for the Democratic Party narrows slightly over the full interval as well.

Finally, for the third panel, we expand the sample to all eligible voters, including those who did not vote in the last presidential election but indicated that they were eligible to do so. For this panel, the proportion of independents again increases after 2008 and reaches its highest point in the midterm election years of 2010 and 
2014. In comparison to 2008, the increase in the proportion of independents appears to be a shift away from both the Democratic Party and the Republican Party.

Overall, these results suggest the emergence of a narrow opportunity for an unconventional candidate to capture the general election in 2016 by assembling an unusual coalition of voters, including eligible voters who had not been mobilized to vote in recent presidential elections. The next step, given our interest in evaluating the specific working-class narratives proposed by others, is to consider whether the pattern depicted in Figure 1 is more pronounced among classes that could be characterized as matching the definition of the working class. ${ }^{14}$

\section{Contours of Social Class}

To transition to models that utilize class as a partition of the electorate, we first offer a brief presentation of the contours of the EGP class schema during the three presidencies, as coded for the GSS. Table 2 presents in its first three columns the distribution of the classes described in Table 1 by pooling four waves of the GSS for each presidency: (1) 1994, 1996, 1998, and 2000 for Clinton; (2) 2000, 2002, 2004, and 2006 for Bush; and (3) 2010, 2012, 2014, and 2016 for Obama. The last three columns report the mean years of completed education for incumbents of these classes.

For the first panel of Table 2, we include all respondents in the restricted analytic sample detailed above: GSS respondents age 25 or older who have a class position because they offered job information, either for a current job or a most recent job. Accordingly, the respondents in the first panel include individuals who may be working part-time, are unemployed, have left the labor force, or are retired. For the second panel, we present the same information for GSS respondents who reported working full-time and who were employed for at least 50 weeks in the prior calendar year.

Although many patterns are represented in Table 2, we offer four observations. First, the similarity across the two panels gives us confidence that we can proceed to analyze the full sample in the first panel because most differences between the overlapping samples are attributable to the age structure of the sample and the prospects for full-time, full-year work among respondents with different skills. However, it should be held in the mind that, for this article, social class refers to whatever current or last occupation is supplied by the GSS respondent. We assume, for example, that a retired lawyer is still a lawyer (and in class I), and so on.

Second, the distributions reported in the first three columns show that the class structure has changed in expected fashion as the postindustrial economy of the United States has continued to evolve. For example, classes I and II have grown while classes VI and VIIa have shrunk. We conclude, however, that the level of change is modest and does not undermine a comparison of class-based party identification across the three presidencies because of any gross compositional shifts.

Third, the mean levels of education across the classes reveal the rough skill hierarchy of the classes. The nonmanual classes I, II, IIIa, and IIIb are ordered precisely as expected. In addition, the service-oriented working class IIIb has a higher average level of education than the semiskilled and unskilled classes VI, 
Table 2: The distribution of social classes across three presidencies, with average levels of education.

\begin{tabular}{|c|c|c|c|c|c|c|}
\hline \multirow[b]{2}{*}{ EGP Class } & \multicolumn{3}{|c|}{ Percent of Total } & \multicolumn{3}{|c|}{$\begin{array}{l}\text { Mean Years of } \\
\text { Completed Education }\end{array}$} \\
\hline & Clinton & Bush & Obama & Clinton & Bush & Obama \\
\hline & \multicolumn{6}{|c|}{ A. All Respondents, Age 25 and Older $(N=29,180)$} \\
\hline I & 8.4 & 9.3 & 10.0 & 16.5 & 16.7 & 16.8 \\
\hline II & 14.8 & 16.2 & 17.3 & 15.7 & 15.8 & 16.0 \\
\hline IIIa & 17.7 & 17.9 & 15.9 & 13.6 & 13.7 & 14.0 \\
\hline $\mathrm{IIIlb}$ & 15.0 & 14.4 & 16.0 & 12.6 & 12.7 & 12.9 \\
\hline IVab & 9.3 & 9.5 & 9.1 & 13.1 & 13.2 & 13.0 \\
\hline IVc & 0.7 & 0.5 & 0.3 & 11.6 & 11.8 & 10.5 \\
\hline V & 7.8 & 8.3 & 7.3 & 13.5 & 13.8 & 13.8 \\
\hline VI & 6.6 & 5.7 & 5.3 & 12.0 & 12.0 & 11.9 \\
\hline VIIa & 18.8 & 16.9 & 17.1 & 11.4 & 11.3 & 11.3 \\
\hline VIIlb & 0.5 & 0.8 & 0.5 & 10.0 & 9.9 & 8.1 \\
\hline \multirow[t]{2}{*}{ Military } & 0.4 & 0.5 & 1.4 & 14.2 & 14.0 & 13.8 \\
\hline & \multicolumn{6}{|c|}{$\begin{array}{l}\text { B. All Respondents, Age } 25 \text { and Older, Who Worked } \\
\text { Full-Time, Full-Year }(N=11,972)\end{array}$} \\
\hline I & 10.9 & 11.1 & 13.0 & 16.6 & 16.8 & 16.9 \\
\hline II & 16.2 & 17.4 & 19.8 & 15.6 & 15.8 & 15.8 \\
\hline IIIa & 17.8 & 18.6 & 17.0 & 13.8 & 13.9 & 14.5 \\
\hline IIIb & 11.2 & 11.3 & 12.0 & 13.0 & 13.2 & 13.4 \\
\hline IVab & 8.1 & 9.1 & 6.8 & 13.5 & 13.3 & 13.2 \\
\hline IVc & 0.6 & 0.3 & 0.3 & 12.4 & 12.7 & 10.1 \\
\hline V & 9.4 & 10.6 & 9.2 & 13.8 & 14.0 & 14.0 \\
\hline VI & 7.8 & 6.5 & 5.3 & 12.3 & 12.3 & 12.4 \\
\hline VIIa & 17.2 & 14.3 & 14.6 & 12.0 & 11.7 & 11.8 \\
\hline VIIb & 0.3 & 0.4 & 0.3 & 12.0 & 11.1 & 6.3 \\
\hline Military & 0.4 & 0.5 & 1.7 & 16.0 & 14.8 & 14.5 \\
\hline
\end{tabular}

Notes: For all results that collapse years, we use a scaled custom weight based on the GSS variables wtssall and wtssnr. We scale these weights to adjust for the relative sample sizes of the GSS in each year so that every GSS survey contributes an equivalent amount of information when we pool survey years. In other words, the mean of the custom weight in each year is scaled inversely to the gross sample size.

VIIa, and VIIb. Finally, the nonprofessional self-employed class IVab as well as the heterogeneous class $\mathrm{V}$ have intermediate average levels of education, which reflect both their internal heterogeneity and unique locations within the class structure. For readers interested in a more complete accounting of class differences of this type, see Morgan (2017), which includes additional differences in demographic characteristics and labor market outcomes, based on analysis of the GSS as well as an aligned sample with millions of respondents from the American Community Survey. 
Fourth, classes IVc, VIIb, and the military are too small to sustain analysis for a data source such as the GSS. Classes IVc and VIIb could be collapsed into other classes, but the tradition of modeling with EGP social classes is to drop these two classes, which are located primarily in agriculture and primary production. The decision to drop individuals in the military, however, is less standard because in many other codings of EGP social classes, individuals in the military are embedded in other classes. We wish we had the sample size to model this "class," given the extent to which current and past military service is thought to shape political preferences, but the sampling scheme of the GSS does not allow it. Not only is the sample size too small, but individuals living in group quarters on domestic military bases and all individuals on foreign bases are excluded from the sampling frame.

\section{Class as a Predictor of Party Identification}

We will offer substantive claims about trajectories of class differences below, using graphical depictions analogous to those presented for the full electorate in Figure 1. A crucial first step is to justify class as a meaningful predictor of party identification, even though readers of class voting debates must surely already be convinced. Nonetheless, Table 3 reports tests of model fit for seven multinomial logit models of party identification, separately for two samples: all individuals who voted in the last presidential election and all individuals who reported that they were eligible to vote in the last presidential election.

The baseline model for each set is one that includes a factor representation of six different periods of time, two unbalanced periods for each presidency. The first period is the first three waves of the GSS in the respective presidency (e.g., 1994, 1996, and 1998 for Clinton) and the second is the transitional election year that concludes each presidency (e.g., 2000 for Clinton). We define periods in this way for three reasons.

First, it is clear (in theory and in the data) that the fourth GSS survey in each presidency (i.e., 2000, 2008, and 2016) should be held separate from other years. In these transitional years, the main contenders for the upcoming general election are known (or almost so) while the GSS is in the field, and thus intended vote for the next president may be entangled with the preferences that shape party identification. Given our interest in the 2016 election, burying the 2016 GSS within an overall Obama period would be unwise, to say the least.

Second, the first of our periods for each presidency includes the first midterm election year, the presidential reelection year, and the second midterm election year. Separating out the reelection year (when party identification may be more sensitive to intended vote) could have been useful, as we know it is for the transitional year at the end of each presidency. Unfortunately, interpretations of patterns in reelection years would be compromised by an unfortunate feature of the timing of the GSS. For 1996 and 2012, the GSS was fielded mostly in its usual interval (spring through early fall), but, for 2004, the GSS was fielded instead at the end of the year, with the majority of interviews conducted after the 2004 votes for president were cast. The results of Figure 1 suggest that there may be a Republican Party bandwagon effect 
among voters, and thus we can mitigate any such effect by smoothing it within the 2002 through 2006 period.

Third, smoothing has advantages because the GSS sample sizes are modest, especially when analysis is ratcheted down to the smaller classes (e.g., class VI). When considered alongside the reasoning above on how to handle the anomalous field period for 2004, smoothing the first three surveys of each presidency mitigates the noise generated by sampling variation, as it reduces the analysis from 12 time periods to only 6 time periods. For comparisons of model fit, of course, smoothed data are not much of an advantage. But, given how we will draw the class-specific figures below to take advantage of smoothing, it seems appropriate to offer model fit results now that are consistent with the figures below. Very similar results would emerge for Table 3 if we defined 12 periods based on each GSS year (and we offer supplementary figures in the online supplement for all 12 time periods for reference, structured just like Figure 1 above).

For the two overlapping samples presented in Table 3, the baseline multinomial logit model includes five dummy variables for period (with associated coefficients for intercepts) across three categories for party (and the fourth as a reference for the outcome). As such, the model absorbs 18 degrees of freedom. Models 2 and 3 are pitted in a classic predictive horse race, measured against the baseline model, with education represented by four dummy variables and class represented by seven dummy variables. These are main-effect-only models, with no period interactions specified to account for education-specific or class-specific trends.

Models 2 and 3 show that both class and education improve model fit considerably, and the likelihood ratio tests in columns 2 through 4 suggest that class does so more strongly. Using information criteria, in which lower values indicate more support for the respective model, Akaike information criterion (AIC) suggests more support for the model with class than for the model with education. However, Bayesian information criterion (BIC) reverses this information ordering because BIC penalizes more heavily for lost degrees of freedom, and class absorbs more degrees of freedom than education.

Model 4 specifies the main effect dummies for both education and class simultaneously. This final model fits best and is favored by both AIC and BIC. Overall, models 1 through 4 suggest that class is a meaningful predictor of party identification, one that is at least as strong as education and probably stronger. Together, class and education are complementary predictors, and neither is reducible to the other (even though, as shown in Table 1, they are strongly related at the aggregate class level).

Models 5 through 7 are analogous to models 2 through 4 but include dummyby-dummy interactions for both class and education with period. Although these models fit the data better, they absorb many more degrees of freedom and as a result are never favored by either AIC or BIC in comparison to models 2 through 4. This pattern could be regarded as one of the first modeling results of this article: based on the AIC and BIC model fit statistics calculated for Table 3, the GSS suggests that party identification has not evolved in class-specific fashion (or, for that matter, in education-specific fashion) over the course of the last three presidencies. We will argue against this inference below using graphical depictions 
Table 3: Relative fit of six-period multinomial logit models of party identification.

\begin{tabular}{|c|c|c|c|c|c|c|}
\hline \multirow[b]{2}{*}{ Model } & \multirow[b]{2}{*}{$\begin{array}{l}\text { Model } \\
\text { degrees of } \\
\text { freedom }\end{array}$} & \multicolumn{3}{|c|}{$\begin{array}{c}\text { Likelihood Ratio Test } \\
\text { Against Baseline Model } 1\end{array}$} & \multicolumn{2}{|c|}{$\begin{array}{c}\text { Model } \\
\text { Information }\end{array}$} \\
\hline & & $\begin{array}{c}\chi^{2} \text { test } \\
\text { statistic }\end{array}$ & $\begin{array}{c}\text { Test } \\
\text { degrees of } \\
\text { freedom }\end{array}$ & $p$ value & $\begin{array}{c}\text { Akaike } \\
\text { information } \\
\text { criterion }\end{array}$ & $\begin{array}{c}\text { Bayesian } \\
\text { information } \\
\text { criterion }\end{array}$ \\
\hline & \multicolumn{6}{|c|}{ A. Voters, Age 25 and Older $(N=20,097)$} \\
\hline 1. Period & 18 & - & - & & 45,320 & 45,462 \\
\hline 2. Period and Education & 30 & 298 & 12 & $<0.01$ & 45,045 & 45,283 \\
\hline 3. Period and Class & 39 & 332 & 21 & $<0.01$ & 45,029 & 45,338 \\
\hline $\begin{array}{l}\text { 4. Period, Education, } \\
\text { and Class }\end{array}$ & 51 & 543 & 33 & $<0.01$ & 44,843 & 45,246 \\
\hline 5. Period by Education & 90 & 396 & 72 & $<0.01$ & 45,068 & 45,779 \\
\hline 6. Period by Class & 144 & 498 & 126 & $<0.01$ & 45,073 & 46,212 \\
\hline \multirow[t]{2}{*}{$\begin{array}{l}\text { 7. Period by Education } \\
\text { and Period by Class }\end{array}$} & 216 & 800 & 198 & $<0.01$ & 44,916 & 46,624 \\
\hline & \multicolumn{6}{|c|}{ B. Eligible Voters, Age 25 and Older $(N=27,522)$} \\
\hline 1. Period & 18 & - & - & & 62,160 & 62,308 \\
\hline 2. Period and Education & 30 & 447 & 12 & $<0.01$ & 61,737 & 61,984 \\
\hline 3. Period and Class & 39 & 504 & 21 & $<0.01$ & 61,698 & 62,019 \\
\hline $\begin{array}{l}\text { 4. Period, Education, } \\
\text { and Class }\end{array}$ & 51 & 728 & 33 & $<0.01$ & 61,498 & 61,917 \\
\hline 5. Period by Education & 90 & 540 & 72 & $<0.01$ & 61,763 & 62,503 \\
\hline 6. Period by Class & 144 & 685 & 126 & $<0.01$ & 61,726 & 62,910 \\
\hline $\begin{array}{l}\text { 7. Period by Education } \\
\text { and Period by Class }\end{array}$ & 216 & 992 & 198 & $<0.01$ & 61,564 & 63,340 \\
\hline
\end{tabular}

Notes: The sample is limited to those who have complete information for education and class, and it excludes individuals in classes IVc, VIIb, and the military (see Tables 1 and 2). The outcome is a four-category party identification variable (Democrat, Republican, another party, and independent) in which independents include leaners. All predictor variables have factor parameterizations: period has six categories, education has five categories, and class has eight categories.

of these results, and we will thereby suggest that global indices of model fit that favor parsimony, such as AIC and BIC, may be less useful for guiding substantive interpretations in this domain than is desired. Moreover, by other model fitting standards, these interactions would be judged meaningful, suggesting that classspecific trends deserve scrutiny. Additional likelihood ratio tests can be calculated from the numbers in columns 2 through 4 , and these would suggest improved model fit along with sufficiently small $p$ values.

Altogether, the results in Table 3 provide basic support for analyzing the relationship between party identification and class position with the GSS data. Class is a meaningful predictor of party identification, and it is at least as predictive 
Voters

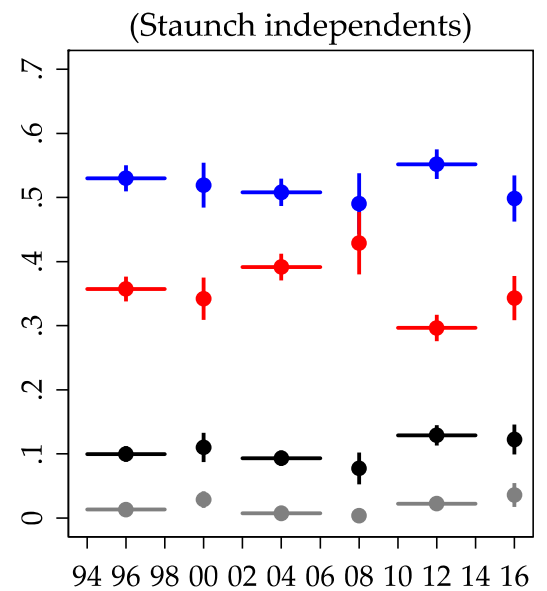

Voters

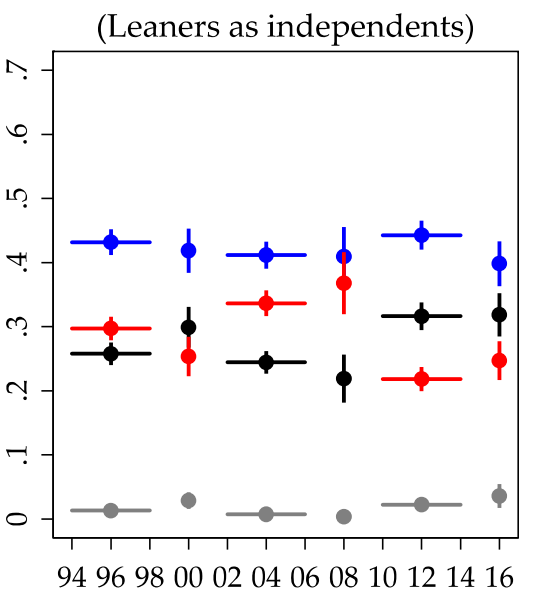

Eligible voters

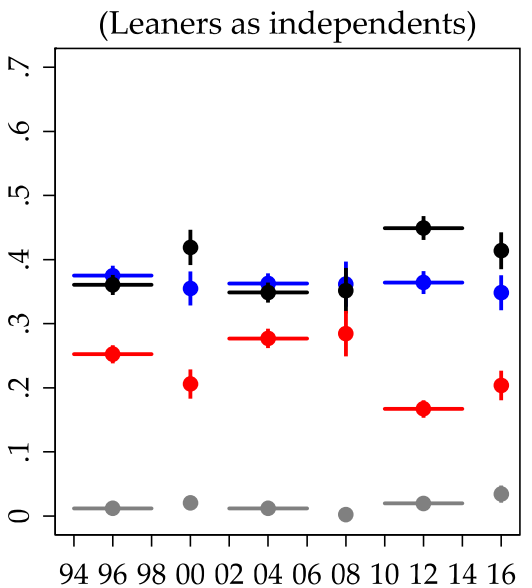

Figure 2: Class IIIb trends in identification with the Democratic Party (blue), Republican Party (red), another party (gray), and independent (black).

as education. In addition, we have some evidence that party identification may have evolved in a class-specific fashion between 1994 and 2016. The next step is to examine the time paths of party preferences by class to determine more conclusively whether interpretable patterns are present.

\section{Party Identification of the Working Class}

In this section and the next, we offer a full presentation of class-specific trajectories in party identification in eight separate figures, broken down across three related samples just as for Figure 1 for the full electorate. We begin with an examination of the three classes most consistent with the definition of the "working class." These are class IIIb (the routine, nonmanual working class, which includes occupations such as cashiers, hairdressers, and retail salespersons), class VI (the skilled manual working class, which includes occupations such as mechanics, carpenters, and machinists), and class VIIa (the semiskilled and unskilled manual working class, which includes occupations such as construction laborers, dishwashers, janitors, and food preparation workers).

Consider first class IIIb, whose party identification patterns are presented in Figure 2, which is structured in the same fashion as Figure 1 . The only difference now is that the sample is restricted to incumbents of class IIIb, and we pool some survey years to generate a six-period model. Accordingly, we provide a horizontal bar as a visual guide for periods that span three GSS survey years (e.g., 1994, 1996, and 1998). We explained the rationale for this type of pooling in the presentation of Table 3 above. (In addition and for comparison, see Figure A2 in the online supplement for an unsmoothed version of Figure 2.)

Like Figure 1, for the first panel of Figure 2, the sample is restricted to individuals age 25 and older who voted in the last presidential election. Likewise, the categorization of party identification for the first panel codes leaners as either 
Democrat or Republican. The bar associated with each point estimate is again equal to plus or minus one standard error, and as such vertical bars are 68-percent confidence intervals.

For the first panel, we see little variation in the proportion that identifies with the Democratic Party, although interpretations surely depend on how daring one wishes to be in ignoring the likely consequences of sampling variation. To our eyes, and in view of the standard errors, the proportion of Democrats is mostly unchanged, with perhaps a slight uptick in identification during the Obama years from 2010 through 2014. In contrast, the proportion of Republicans is more dynamic, seeming to rise meaningfully between the 2000 and 2008 elections, and then falling during the Obama years from 2010 to 2014 . This decline appears to coincide with proportional increases for all other options, including staunch independence and another party. In 2016, finally, we see a small rebound for the proportion of Republicans, but the gap with the proportion of Democrats remains large, about the same as during the Clinton presidency.

Before carrying on, we should stop to take a position on sampling variation. Notice that the standard errors are larger for the election years of 2000, 2008, and 20016. Recall that these are represented by single GSS survey years rather than three pooled GSS survey years, as is the case for the other three time points. It is important to compare "like with like," so that, for example, one recognizes that the yawning gap between Democrat and Republican for the Obama years in 2010 through 2014 is based on three times as much information as the smaller election-year differences that surround it in 2008 and 2016. Thus, it would not be correct to write off the 2010 through 2014 difference as the product of more sampling variation than other differences in the figure.

For the second panel of Figure 2, we move independents who lean Democrat or Republican into a broader category that includes all staunch and leaning independents. Although the proportion of Democrats is lower, the trend is similar, if a bit reduced in magnitude. For the proportion of Republicans, the trend is also unchanged, but may be accentuated. What is most noticeable, relative to the first panel, is that the proportion of independents rises to its highest level in 2010 through 2014 and then remains in the same place for 2016 (although with a larger standard error). This change is consistent with meaningful party dealignment for this segment of the working class, during which the salience of traditional party identification may have eroded meaningfully during the Obama presidency. If so, the pattern is more strongly away from the Republican Party than the Democratic Party.

Finally, for the third panel, we expand the sample to all eligible voters, including those who did not vote in the last presidential election but indicated that they were eligible to do so. These patterns are harder to interpret, but also, we think, among the most interesting (especially for other working classes below). Here, we now see that the proportion of independents is at its highest point in 2010 through 2014, followed by 2000 and 2016, which were both election years in which Democrats lost the presidential election very narrowly. The difference, however, in these years, appears to be shifts away from the proportion of Republicans. So, although again, with this broader group of individuals, the salience of party identification seems to 
Voters

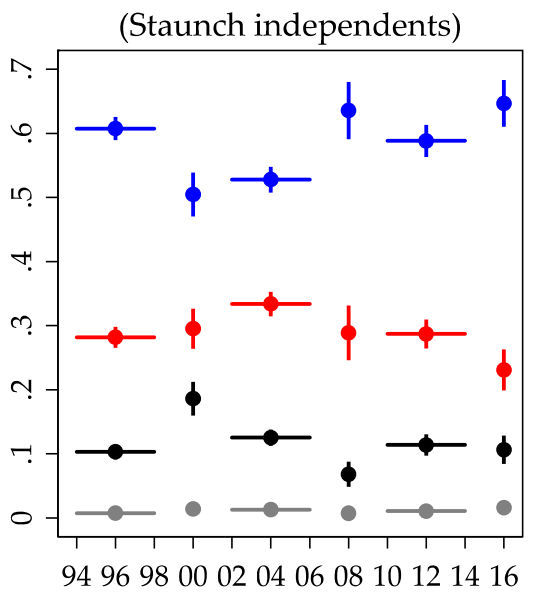

Voters

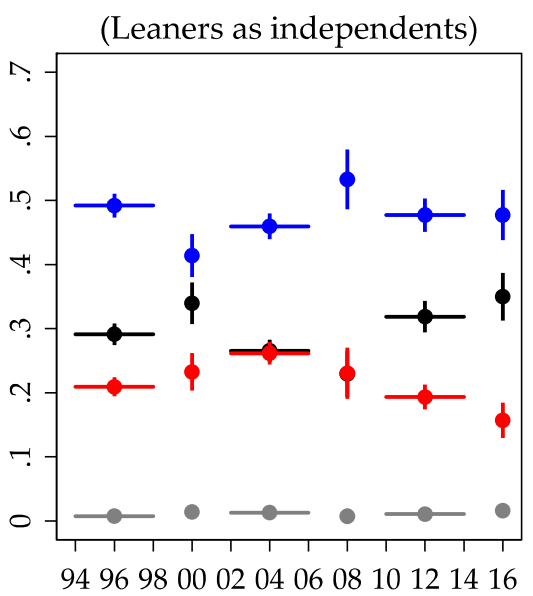

Eligible voters

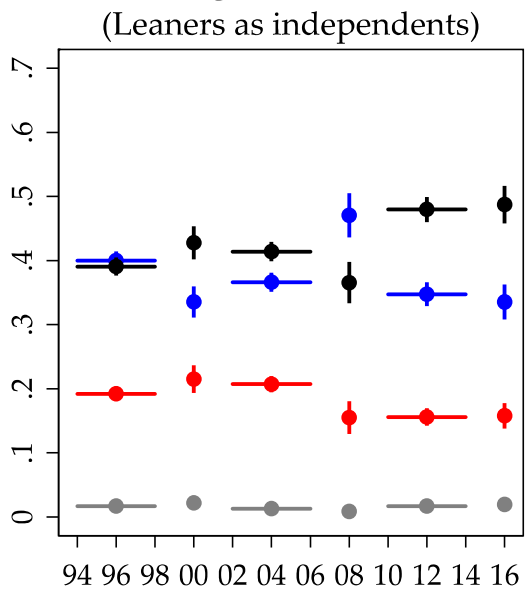

Figure 3: Class VIIa trends in identification with the Democratic Party (blue), Republican Party (red), another party (gray), and independent (black).

have declined since 2008, this change reflects movement away from the Republican Party rather than from the Democratic Party.

Consider now Figures 3 and 4, which offer the same three-panel depiction of party identification but now for the manual working classes, with class VI and class VIIa differentiated mainly by level of skill and all that is determined by it (see Table 2 for mean differences in education). Following the same basic interpretation strategy, we can see some similar patterns. Consider class VIIa first, which in some ways is the class most similar to class IIIb just considered. Here, in Figure 3, we see that among voters, with leaners categorized as Democrats or Republicans, the proportion of Democrats is by far the highest. It is higher in the Clinton and Obama presidencies than the Bush presidency, and appears to be elevated in both the 2008 and 2016 election years. The proportion of Republicans increases during the Bush presidency but then declines.

For the second panel of Figure 3, we recode the leaners, and now the decline in the proportion of Republicans after 2008 is more substantial. Now we see also a decline after 2008 during the Obama presidency in the proportion of Democrats, suggesting that, more than for class IIIb, the growth of weakly identified voters during the Obama years and in 2016 is produced by shifts away from both parties. Finally, for the third panel of Figure 3, we include all eligible voters, not just those who voted in the last presidential election. Here, during the Obama years and the 2016 election year, the proportion of independents is higher. The proportion of Democrats is likewise lower than it was in 2008. For class IIIb, it appeared that solid Republicans had lost ground to merely leaning Republicans. For class VIIa, we have an analogous pattern for Democrats. Some members of both classes moved away from solid identification with one party, collectively increasing the number of eligible voters without a strong attachment to either the Democratic Party or the Republican Party. 
Voters

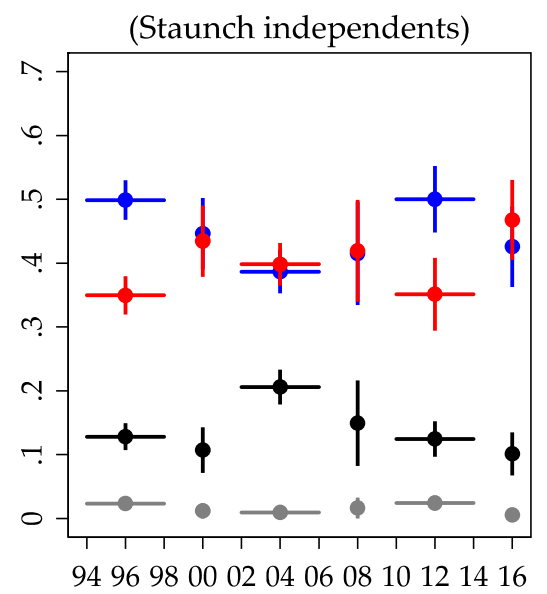

Voters

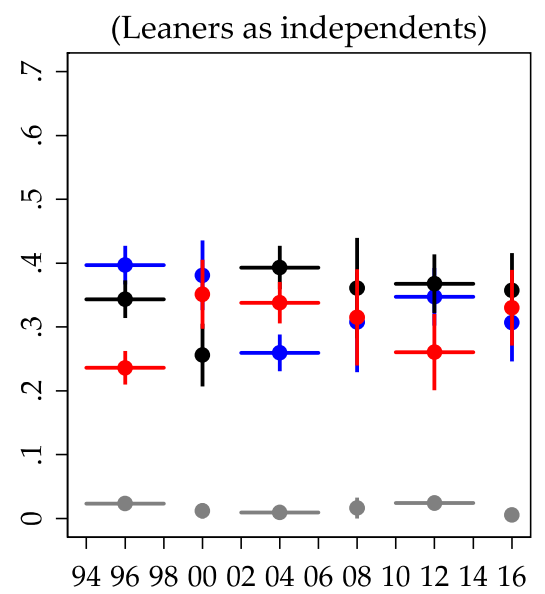

Eligible voters

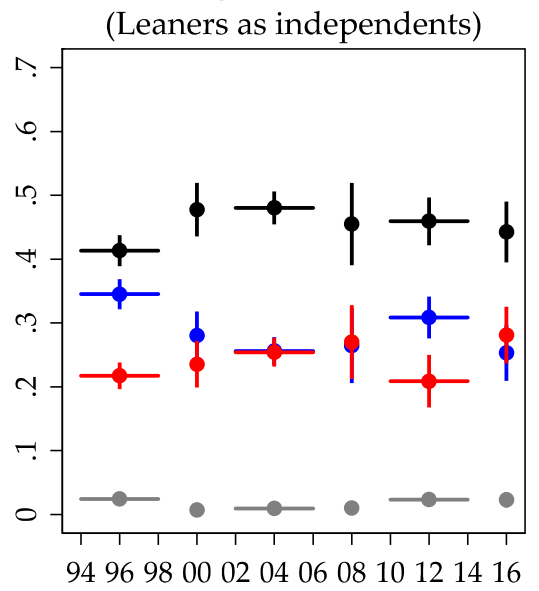

Figure 4: Class VI trends in identification with the Democratic Party (blue), Republican Party (red), another party (gray), and independent (black).

Figure 4 presents results for the more highly skilled manual working class. Class VI is smaller, and as a result the standard errors for Figure 4 are considerably larger. Accordingly, for the first panel, it is difficult to discern a trend among voters. There appears to be near parity in election years, along with relative support for the president's party in other years. Thus, for class VI, the Democratic Party has not held the strong position that it has enjoyed among voters in classes IIIb and VIIa. For the second panel, the recoding of leaners also suggests little evidence of a trend, but it is notable that there is no evidence, again, of Democratic Party dominance. But, then, for the third panel, a clear pattern emerges. Among all eligible voters, the proportion of independents is the largest in all six time periods. The second and third panels reveal a large proportion of independents in class VI, suggesting that, even more prominently than for classes IIIb and VIIa, class VI includes a substantial pool of eligible voters that could be mobilized for by an unconventional presidential candidate.

\section{Party Identification for Other Classes}

For Figures 5 through 7, we consider classes at the other end of the skill distribution: class I (higher-grade professionals, administrators, and managers, which includes occupations such as physicians, accountants, engineers, management analysts, and postsecondary teachers), class II (lower-grade professionals, administrators, and managers, which includes occupations such as elementary school teachers, human resources managers, computer programmers, and registered nurses), and class IIIa (higher-grade routine nonmanual service employees, which includes occupations such as bookkeeping clerks, secretaries, computer support specialists, and licensed vocational nurses).

In comparison to the patterns just presented for the working classes IIIb, VI, and VIIa, we see in these next three figures for classes I, II, and IIIa a much different 
Voters

(Staunch independents)

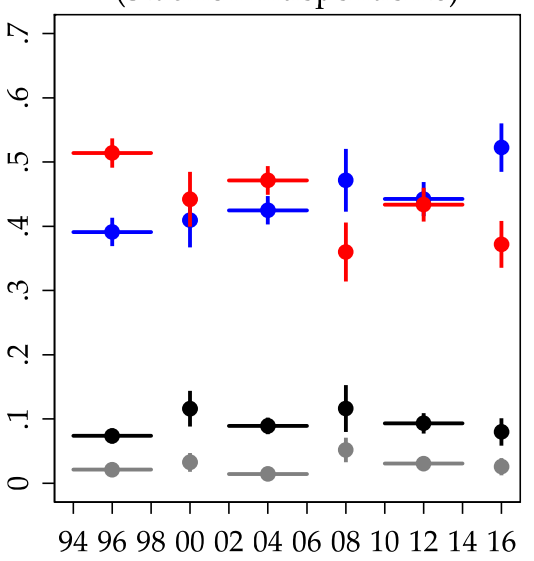

Voters

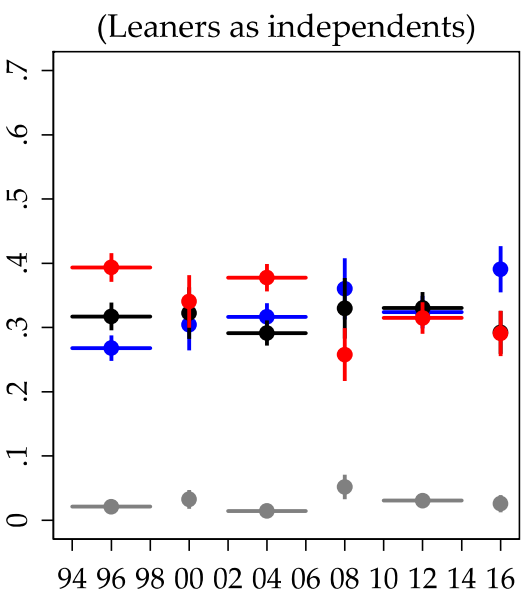

Eligible voters

(Leaners as independents)

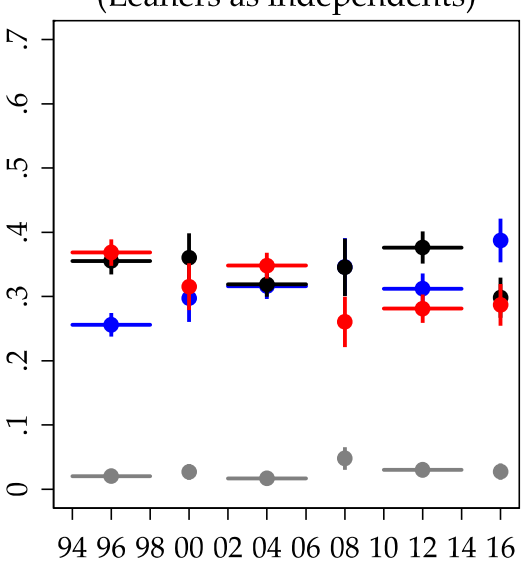

Figure 5: Class I trends in identification with the Democratic Party (blue), Republican Party (red), another party (gray), and independent (black).

Voters

(Staunch independents)

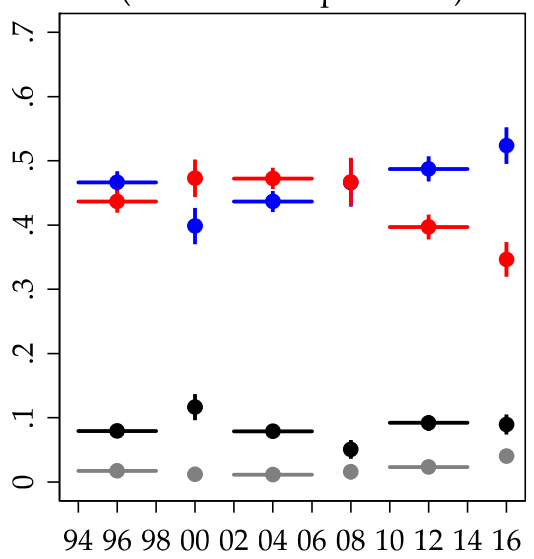

Voters

(Leaners as independents)

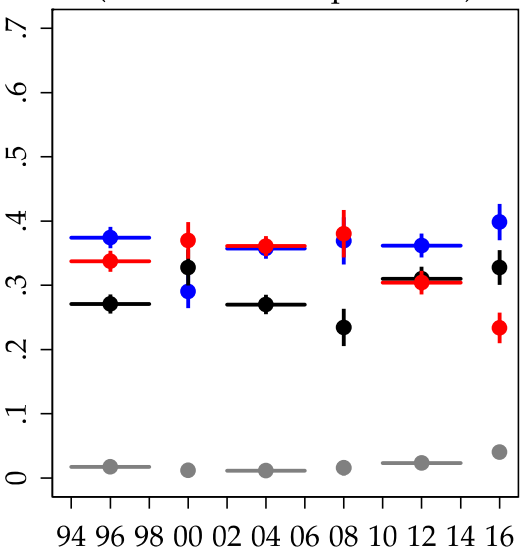

Eligible voters

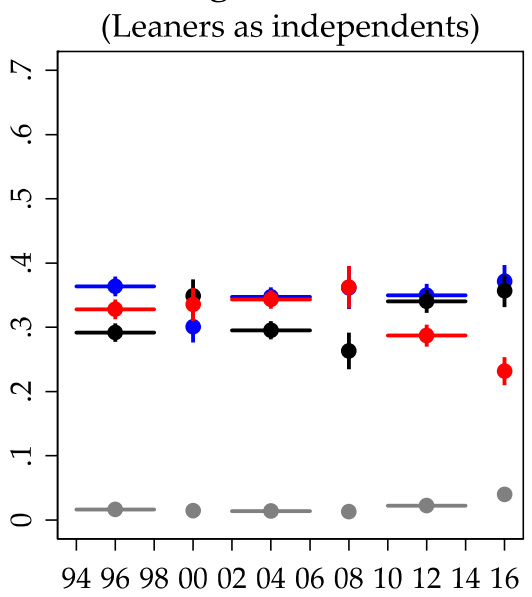

Figure 6: Class II trends in identification with the Democratic Party (blue), Republican Party (red), another party (gray), and independent (black).

pattern. So as not to get bogged down in detailed reporting of these trends, having demonstrated above how we are inclined to interpret these sorts of results, we offer in this section only the highlights of these three figures.

Voters in class I have trended Democratic during these three presidencies, with particularly strong support for the Democratic Party in the election years of 2008 and 2016 and a slight countertrend during the Obama presidency toward parity. These trends do not vary with the alternative coding of independents, and little change emerges when the sample is widened to all eligible voters, primarily because the rate of self-reported past voting is much higher for class I than for the working class. 
Voters Voters Eligible voters

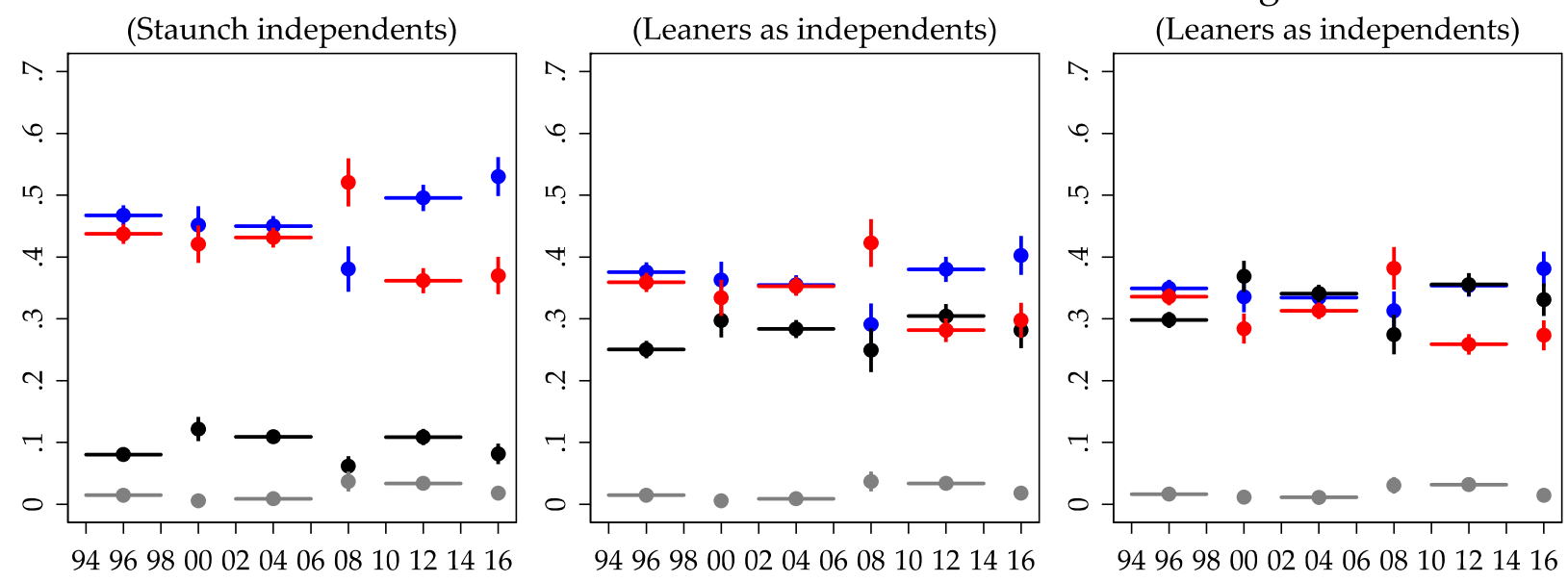

Figure 7: Class IIIa trends in identification with the Democratic Party (blue), Republican Party (red), another party (gray), and independent (black).

Voters in class II are very similar to voters in class I, although the timing of the increase in the proportion of Democrats varies, perhaps genuinely or because of sampling error. Class II is larger than class I, and so if sampling error is the source of the divergence, one should have more confidence in the trend for class II than for class I. We see parity for the proportions of Republicans and Democrats for the 2008 election year, although by 2016 a wide gap in favor of the Democratic Party is apparent. For class II, unlike class I, it appears that the recent increase for the proportion of Democrats is among leaning Democrats. Finally, as with class I, expanding the sample to include all eligible voters does not change the patterns nearly as much as for the working classes IIIb, VI, and VIIa.

Class IIIa is similar to class II, although we are not sure what to make of the surprisingly high proportion of Republicans in 2008. Although we would be inclined to chalk this increase up to anomalous sampling variation, it is possible that John McCain was particularly appealing to members of class IIIa (perhaps because of his military background), but we do not know. Aside from this puzzling jump in 2008, we see class IIIa following a pattern similar to class II, with trends that are a little less dynamic and without an additional falloff in the proportion of Republicans in 2016.

This accounting of class-based trajectories leaves two remaining classes. For Figures 8 and 9, we present analogous results for class $V$ (the heterogeneous class composed mostly of higher-grade technicians and repairers, public safety workers, and supervisors of manual workers, which includes occupations such as drafters, clinical laboratory technicians, firefighters, police officers, construction managers, and first-line supervisors of production workers) as well as class IVab (nonprofessional self-employed workers, which includes self-employed incumbents of all occupations otherwise assigned to classes IIIa, IIIb, V, VI, and VIIa). 
Voters

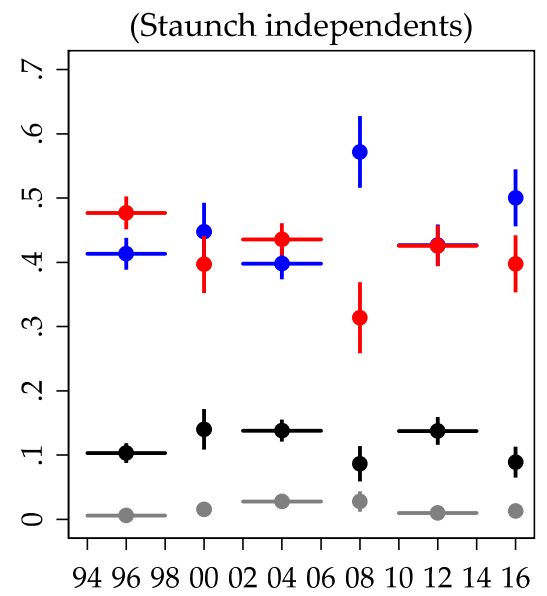

Voters

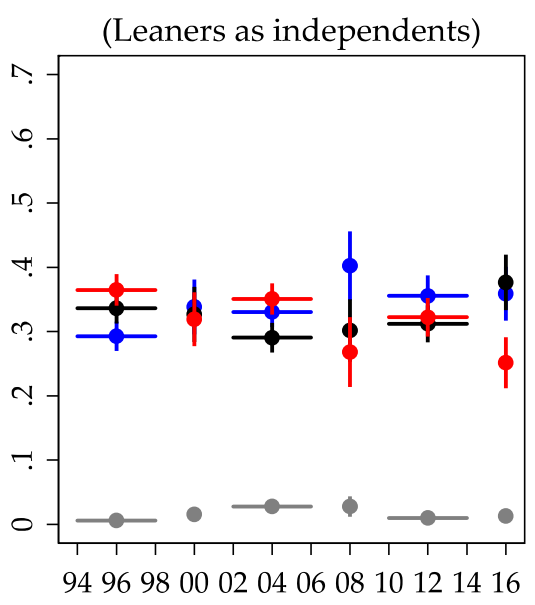

Eligible voters

(Leaners as independents)

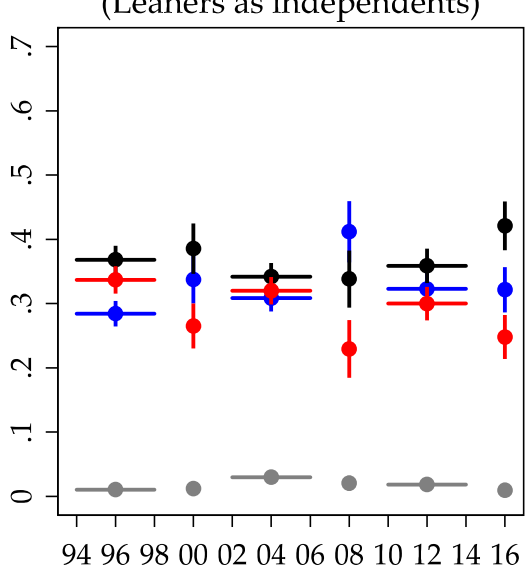

Figure 8: Class V trends in identification with the Democratic Party (blue), Republican Party (red), another party (gray), and independent (black).

Voters

(Staunch independents)

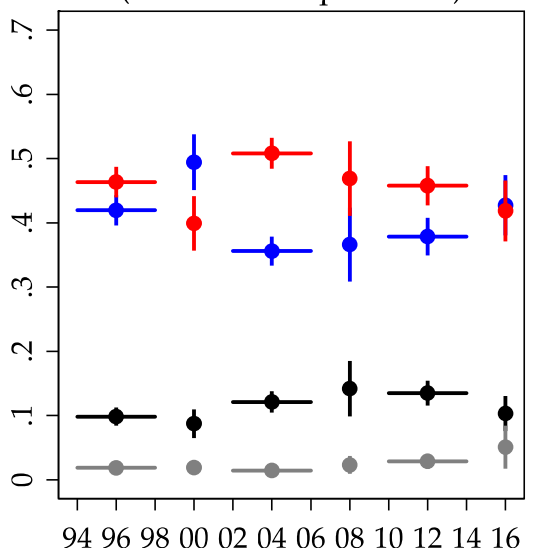

Voters

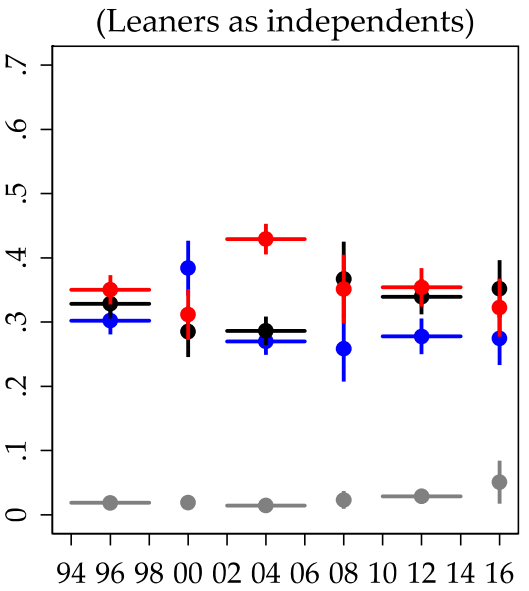

Eligible voters

(Leaners as independents)

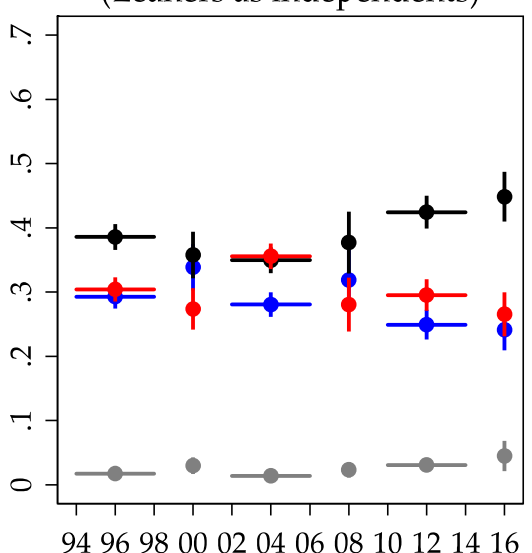

Figure 9: Class IVab trends in identification with the Democratic Party (blue), Republican Party (red), another party (gray), and independent (black).

As revealed in Figures 8 and 9, the trajectories for these two classes are much closer to the pattern revealed for the working classes IIIb, VI, and VIIa than for classes I, II, and IIIa. Figure 8 shows that for the relatively small but highly varied class $\mathrm{V}$, voters identified in mixed fashion, with a surprising swing toward the Democratic Party in 2008 and a less pronounced one in 2016. The recoding of leaning independents for the second panel dampens the 2008 increase and accounts for the 2016 increase, indicating that the swing was disproportionately among independents who leaned Democrat. When all eligible voters are included in the sample, as in the third panel, we see a very small increase during the Obama 
presidency in independents of all types, which then increases further in 2016. In comparison to 2008, independents became the largest group among eligible voters in 2016, as we showed above was also the case for the working classes IIIb, VI, and VIIa.

For Figure 9, which presents the same results for the nonprofessional selfemployed individuals in class IVab, the proportion of Republicans is typically slightly higher than the proportion that is Democratic. However, the standard errors are comparatively large in the three election years, and here we see substantial fluctuation in the point estimates. When the sample is widened to include all eligible voters in the third panel, additional clarity emerges. The proportion identifying as independent grew substantially during the Obama years and continued to grow into the 2016 election year. This rise is similar to the same one shown already for classes IIIb, V, and VIIa, which brings all of these classes closer in line with the already prevailing dominance of independents among eligible voters in class VI.

Altogether, these final two sets of results support a simple common finding: the prevalence of eligible voters who identified as independents in response to the first question on the GSS survey rose during the Obama presidency-and especially during the 2016 election year-for most of the classes that can plausibly be interpreted as "working class." The skilled working class VI, which showed no additional increase, already had the highest proportion of independents. Relatedly, none of the classes that could be characterized as non-working class, which are classes I, II, and IIIa, showed the same pattern. Here, independents were not particularly prominent, either among voters or when the sample is expanded to all eligible voters.

\section{Conclusions}

The GSS reveals substantial change in party identification across the last three two-term presidencies of Bill Clinton, George Bush, and Barack Obama. Given present concerns, the last set of changes is the most important to recapitulate here. On the eve of the 2016 election, and for several years prior, eligible voters in the working class were less attached to the Democratic Party. Their loyalties had not shifted to the Republican Party, and the evidence suggests that the Republican Party also lost some of its loyalists. Altogether, the proportion of the working class that identified as independent increased. With this softening of party identification, a candidate who could appeal to working class voters who were disaffected within the Democratic Party but who were still uncomfortable with many of the positions of the establishment Republican Party had an emergent opportunity for electoral success.

These patterns aside, we do not wish to overstate the scale of the changes that our results document. These shifts are typically between 6 and 10 percent of the working class, depending on which specific EGP class is considered. As a result, the Democratic Party did not lose much of its working-class advantage to the Republican Party, especially among those who reported having voted in the most recent presidential election. Rather, the aggregate pool of eligible voters moved, over the course of the Obama presidency, to a slightly more independent 
status. As a result, the prospects increased that segments of the working class could be mobilized by an unconventional candidate who did not hue too closely to the positions of the establishment Republican Party that had held little appeal for them in the past. Still, they needed to be mobilized to vote because many of these individuals indicated that they had not voted in the last presidential election.

For the academic literature on party identification, the implications of these results are threefold. First, contradicting the traditional attachment position, these results line up with the alternative position that shifts in party identification are a leading indicator of electoral outcomes. Further evidence may accumulate for this position when the retrospective voting data become available following the release of the 2018 GSS. Second, social class can be a structural dimension of dealignment and is an obvious candidate during periods when gains from economic growth are unevenly distributed. Third, moments of party dealignment can emerge, and these may be encouraged by the polarization of those elected to office. We present no direct evidence in this article that voters who turned away from both parties had centrist proclivities or aversion to the ineffective government that polarization can yield (but see Morgan and Kang 2015 for evidence of the centrist policy preferences held by GSS respondents who identified as independents between 2010 and 2014). Nonetheless, this pattern is consistent with the "sorting" argument of others that those who remain fully identified with traditional parties in recent years appear more polarized. ${ }^{15}$

\section{Discussion}

Our analysis does not reveal why eligible voters in the working class were more likely to move away from clear identification with the Democratic Party and Republican Party during the Obama presidency. Some likely factors are those frequently discussed by journalists: a slow economic recovery following the recession, a failure by those in office to prosecute the individuals responsible for the collapse of financial institutions, and the continuation of the decades-long relative erosion in the real wages of semiskilled and unskilled workers, which is a trajectory Democrats may have come to own from 2009 onward after taking control of all three branches of the federal government.

All of these very same reasons may explain why voters in classes I, II, and IIIa, on average, became even more loyal to the Democratic Party. Classes I and II were more likely to benefit from the continuing growth of inequality, and all three of these classes were less affected by the slow recovery from the recession. Given their growing relative affluence and stability, individuals in these classes also may have come to support more strongly the postmaterialist issues embraced by the Democratic Party, including support for combatting climate change and legal developments in response to new forms of gender identification and marriage. Having acquired more postsecondary education, many members of these classes may have been more attracted to the tolerance of diversity that decades of research has shown is cultivated by engagement with institutions of higher education.

The silver lining for Democrats, among those looking for one, is that dealigned eligible voters within the working class appear not to have thrown their support 
to a Republican candidate who maintained positions fully consistent with the Republican Party's traditional platform. Instead, those who seem to have switched allegiance threw their support to a candidate-perhaps during primary crossover voting, and very likely during the general election-who promoted positions closer to their economic interests. That these positions were also nativist and xenophobic is undeniable, and so the lead lining of those same clouds for the polity as a whole is that the particular nature of the Republican candidate's appeals to workingclass economic interests were not deemed sufficiently noxious to prevent electoral success. ${ }^{16}$ Rejection of the civil rights agenda, however defined, appears fashionable again among a larger share of the population than most observers assumed was possible before the 2016 election cycle commenced.

Although this article is the first direct assessment of the class trajectories of party identification in the run-up to the 2016 election, some of the broad outlines of our explanation are not new. Journalists and commentators in the field during the 2016 election cycle offered narrative explanations that suggested working-class voters, especially those who self-identify as white, were more attracted to the Republican candidate than many pundits had expected. And even though pollsters do not spend the needed resources to carefully collect data on individuals' occupations, their polls did reveal an emerging education deflection in patterns of intended presidential vote.

In other regards, journalists did not have the story correct, seeing the 2016 election cycle as more of a discrete break with the Obama years than the academic literature would (and did) suggest. The GSS, for example, showed that the electorate was moving away from many left-leaning policy positions between 2010 and 2014, even among Democrats and independents (see Morgan and Kang 2015, Tables 2 and 3). Furthermore, recent ethnographic field research during the Obama presidency pointed to similar shifts, with, for example, an incisive study of southern Tea Party supporters reaching conclusions very similar to a concurrent study of rural residents of Wisconsin that included many Democrats (see Hochschild 2016 and Cramer 2016). Fieldwork conducted during the 2016 election cycle will be similarly revelatory, we expect, and some results from Pennsylvania already line up well with the interpretations offered here (Silva 2017). In addition, some scholars have argued that the rise of an authoritarian impulse among many voters is a crucial new trend, which is sorting many voters of all types away from the Democratic Party and toward the Republican Party (see, for example, Hetherington and Weiler 2009). Although measurement controversies will always plague studies of authoritarianism, these studies claim that the working class is overrepresented among those who score high on preferences for authoritarian leadership, at least when class is measured coarsely by level of education. ${ }^{17}$

Finally, the instability in the loyalty of the working class is not a new phenomenon, nor one that has escaped the attention of many past social scientists. For example, in their classic study of the 1948 presidential election in Elmira, New York, the team of Berelson et al. ([1954] 1986) wrote that

... the political history of the last twenty years in this country reveals a number of actual and potential clashes between economic interests of the different classes. What this seems to mean in Elmira is that the 
workers are in an ambivalent position in which their political values are derived from the dominant culture at the same time that their interest in social prestige and economic security is to some extent blocked by the interests of the dominant groups. American cultural values and actual life-experience are mutually reinforcing for upper and middle classes in the society, and accordingly they exhibit a high degree of political consensus. But cultural values and life-experience are often in contradiction for the workers, and accordingly they are more ambivalent and, as we shall see, more unstable in their political support. It takes a depression or a heated political campaign directly aimed at economic interest to bring out their "class vote" sharply against the norms of the "larger community." (P. 59).

Replace the "Elmira" in this quotation from 1954 with any of the northern swing states in 2016, and the same explanation still has purchase. It suggests why many working-class voters, who had come to believe that the American Dream was compromised by elite support of globalization and multiculturalism, were willing to vote for a billionaire who appealed directly to their interests, using tactics that roiled most of the electorate. The future success of the same strategy is likely to determine whether a new equilibrium in party identification will emerge.

\section{Notes}

1 As of the July 2016 data release, the verbatim responses to the questions on jobs and job activities for all past GSS respondents were recoded to the consistent and detailed 539-cateogory 2010 US Census Occupational Classification. This is the same coding scheme that has been used for GSS respondents since 2012.

2 This book gathers together and extends a series of influential articles from the 1990s, and the most important one is Brooks and Manza (1997), which builds on many of the arguments first developed in Hout, Brooks, and Manza (1995).

3 For collections of research on these debates, see Evans (1999b) and Clark and Lipset (2001). These debates took off following the analysis of voting in British elections in the 1980s (see Heath et al. 1991 and references to prior work therein), and they were fortified by general arguments about the rising importance of postmaterialist values among voters (see Inglehart 1977, 1997, and Clark and Lipset 1991). Many excellent reviews of these debates are available, from Evans (1999a) to Weakliem and Adams (2011).

4 They also provide evidence that professionals, rather than managers, led this shift.

5 Manza and Brooks (1999:43) offer this explanation for their focus on presidential election voting: "Party identification tends to change much more slowly and tends to follow, not precede, changes in presidential voting." This was the standard position in comparative analysis of class voting at the time (and with good reason, given measurement complications, as shown by Katz 1979 and Blais et al. 2001). None of the pieces in the Evans (1999b) volume, for example, model party identification alongside voting or as part of the process that generates voting. Separate from the class voting debate, some sociological literature has considered party identification patterns in the United States in an intergenerational framework (see Knoke 1972 and Knoke and Hout 1974), but attention has fallen away very substantially since then. 
6 The 1954 study used a five-category classification of socioeconomic status based on three dimensions: a dichotomy for the occupation of the breadwinner of the household ("professional, semiprofessional, managerial, executive, and clerical-sales" vs. "skilled labor, semiskilled, unskilled, and service workers"), a dichotomy for the respondent's education (a high school diploma or higher vs. less than a high school diploma), and a four-category interviewer rating, from A to D, of the household's "economic level," with the C category further broken down to C+ or C- based on the "ownership of common household utilities." See Berelson et al. ([1954] 1986:54-61, 368-69). The authors used the language of social class because their socioeconomic index, which they sometimes wrote of as "socioeconomic class index," gave evidence of "class voting." They also showed that their index aligned to a substantial degree with respondents' subjective social class, in response to the question "By and large do you think of yourself as being in the upper class, the upper middle, the middle, the lower middle, or the lower class?" (Berelson et al. [1954] 1986:351).

7 See Lewis-Beck et al. (2008) for an update to the volume, based on analysis of the 2000 and 2004 ANES data. Manza and Brooks (1999:Chapters 2 and 3) offer an excellent review of the connections between this Michigan perspective and other approaches to left-right class voting, especially the comparative work of Lipset and his colleagues. Here, we consider only models of party identification.

8 Although Campbell et al. (1960) is the classic statement, refinements to the overall framework can be found in Converse $(1964,1969)$, and defenses of the approach can be found in pieces like Miller (1991). Converse (2006:605-6) offers a narrative history of the explanation, describing how his funnel of causality emerged in response to competition with sociologists.

9 See both Fiorina (2002) and Green, Palmquist, and Schickler (2002), which review these debates from somewhat differing perspectives.

10 Over time, even the most stalwart defenders of the emotional attachment position moved just a bit toward a middle-road position, accepting that there are periods when fluctuations in party identification line up with electoral change, weakly at least and with the direction of causality unclear (e.g., compare Green and Palmquist 1994 and Gerber and Green 1998 to Green et al. 2002).

11 We do not mean to imply that no new theoretical work has emerged (see, e.g., Jackson and Kollman 2011 as well as Sniderman and Stiglitz 2012). In addition, more recent empirical work has sought to delineate how patterns of party identification have interacted with issue polarization, ideology, core values, and geography. For representative work, see Keele and Wolak (2006), Levendusky (2009), Wright and Birkhead (2014), Iyengar and Westwood (2015), and Miller and Conover (2015). A new wave centered on the 2016 election is surely forming now.

12 The GSS has been offered with both English and Spanish questionnaires (and appropriate interviewers) from only 2006 onward (see Smith et al. 2017). As a result, although the GSS is now considered a national sample of English and Spanish speakers, prior to 2006 it was a sample of individuals willing to take a survey in English, which includes individuals whose primary language may be one other than English. Even now, the GSS should be seen as a national sample of individuals willing to take a survey in either English or Spanish. Work is needed to understand response patterns for all language groups and to fashion techniques for adjusting the GSS when data before and after 2006 are used together. This work is beyond the scope of this article.

13 We do not use the parallel follow-up question, "If Republican or Democrat: Would you call yourself a strong [Republican/Democrat] or not a very 
strong [Republican/Democrat]?", which can be used to separate Democrats into "Strong" and "Not very strong" and Republicans into "Strong" and "Not very strong."

14 To bridge the analysis in this section with the analysis below, we offer two additional figures in the online supplement. In Figure A1-A, we redraw Figure 1 after excluding those who do not report a current or past occupation (and thus have no EGP social class). For Figure A1-B, we then further exclude those who are in the three small classes (IVc, $\mathrm{VIIb}$, and military). The patterns of party identification do not change, primarily because the excluded groups are small.

15 Altogether, we are drawn to the position of pieces that argue for cycles of party identification equilibria, punctuated by meaningful party realignments, such as the mover-stayer model of Clarke and McCutcheon (2009) and the realignment analysis of Meffert, Norpoth, and Ruhil (2001).

16 See Hajnal and Rivera (2014) for a focus on how sentiment toward immigrants may be shaping party identification.

17 This stream of scholarship has led commentators like Judis (2016) to draw attention to a piece of sociology - the 1976 book The Radical Center: Middle Americans and the Politics of Alienation by Warren-that, if citation counts are to be trusted, appears to have fallen off the radar of all current scholarship in sociology and political science. Parts of Warren's book feel as if they could have been written in 2016 rather than 1976, and some of the older subjects in Hochschild (2016) might have been respondents to Warren's survey. It also aligns nicely with current work on authoritarianism.

\section{References}

Abramson, Paul R., and Charles W. Ostrom. 1991. “Macropartisanship: An Empirical Reassessment." The American Political Science Review 85(1):181-92. https : //doi .org/10. 2307/1962884

Abramson, Paul R., and Charles W. Ostrom. 1994. "Question Wording and Partisanship: Change and Continuity in Party Loyalties During the 1992 Election Campaign." The Public Opinion Quarterly 58(1):21-48. https://doi .org/10.1086/269406

Achen, Christopher H. 1992. "Social Psychology, Demographic Variables, and Linear Regression: Breaking the Iron Triangle in Voting Research." Political Behavior 14(3):195-211. https://doi.org/10.1007/BF00991978

Achen, Christopher H. 2002. "Parental Socialization and Rational Party Identification." Political Behavior 24(2):151-70. https://doi.org/10.1023/A:1021278208671

Berelson, Bernard, Paul Felix Lazarsfeld, and William N. McPhee. [1954] 1986. Voting: A Study of Opinion Formation in a Presidential Campaign. Chicago: University of Chicago Press.

Blais, André, Elisabeth Gidengil, Richard Nadeau, and Neil Nevitte. 2001. "Measuring Party Identification: Britain, Canada, and the United States." Political Behavior 23(1):5-22. https://doi.org/10.1023/A:1017665513905

Brooks, Clem, and Jeff Manza. 1997. "Class Politics and Political Change in the United States, 1952-1992." Social Forces 76(2):379-408. https : //doi .org/10.2307/2580718

Campbell, Angus, Philip E. Converse, Warren E. Miller, and Donald E. Stokes. 1960. The American Voter. New York: Wiley.

Clark, Terry Nichols, and Seymour Martin Lipset. 1991. "Are Social Classes Dying?" International Sociology 6(4):397-410. https://doi .org/10.1177/026858091006004002 
Clark, Terry Nichols and Seymour Martin Lipset, eds. 2001. The Breakdown of Class Politics: A Debate on Post-Industrial Stratification. Baltimore: Johns Hopkins University Press.

Clarke, Harold D., and Allan L. McCutcheon. 2009. “The Dynamics of Party Identification Reconsidered." The Public Opinion Quarterly 73(4):704-28. https://doi .org/10.1093/ poq/nfp051

Converse, Philip E. 1964. "The Nature of Belief Systems in Mass Publics." Pp. 206-61 in Ideology and Discontent, edited by D. E. Apter. London: Free Press of Glencoe.

Converse, Philip E. 1969. "Of Time and Partisan Stability." Comparative Political Studies 2(2):139-71. https://doi.org/10.1177/001041406900200201

Converse, Philip E. 2006. "Researching Electoral Politics." The American Political Science Review 100(4):605-12. https://doi .org/10.1017/S0003055406062484

Cramer, Katherine J. 2016. The Politics of Resentment: Rural Consciousness in Wisconsin and the Rise of Scott Walker. Chicago: University of Chicago Press. https ://doi .org/10.7208/ chicago/9780226349251.001.0001

Erikson, Robert, and John H. Goldthorpe. 1992. The Constant Flux: A Study of Class Mobility in Industrial Societies. Oxford: Oxford University Press.

Erikson, Robert, John H. Goldthorpe, and Lucienne Portocarero. 1979. "Intergenerational Class Mobility in Three Western European Societies: England, France and Sweden." The British Journal of Sociology 30(4):415-41. https ://doi . org/10.2307/589632

Erikson, Robert S., Michael MacKuen, and James A. Stimson. 2002. The Macro Polity. New York: Cambridge University Press.

Evans, Geoffrey. 1999a. "Class Voting: From Premature Obituary to Reasoned Appraisal." Pp. 1-20 in The End of Class Politics? Class Voting in Comparative Context, edited by G. Evans. Oxford: Oxford University Press. https://doi.org/10.1093/0198296347.003.0001

Evans, Geoffrey, ed. 1999b. The End of Class Politics? Class Voting in Comparative Context. Oxford: Oxford University Press. https://doi.org/10.1093/0198296347.001.0001

Fiorina, Morris P. 1981. Retrospective Voting in American National Elections. New Haven: Yale University Press.

Fiorina, Morris P. 2002. "Parties and Partisanship: A 40-Year Retrospective." Political Behavior 24(2):93-115. https://doi.org/10.1023/A:1021274107763

Gerber, Alan, and Donald P. Green. 1998. "Rational Learning and Partisan Attitudes." American Journal of Political Science 42(3):794-818. https : //doi . org/10 . 2307/2991730

Goldthorpe, John H. 1999. "Modelling the Pattern of Class Voting in British Elections, 19641992." Pp. 59-82 in The End of Class Politics? Class Voting in Comparative Context, edited by G. Evans. Oxford: Oxford University Press. https ://doi .org/10.1093/0198296347. 003.0003

Green, Donald Philip, and Bradley Palmquist. 1994. "How Stable Is Party Identification?". Political Behavior 16(4):437-66. https : //doi .org/10.1007/BF01498826

Green, Donald P., Bradley Palmquist, and Eric Schickler. 2002. Partisan Hearts and Minds: Political Parties and the Social Identities of Voters. New Haven: Yale University Press.

Hajnal, Zoltan, and Michael U. Rivera. 2014. "Immigration, Latinos, and White Partisan Politics: The New Democratic Defection." American Journal of Political Science 58(4):773-89. https://doi.org/10.1111/ajps.12101

Heath, Anthony, Roger Jowell, John Curtice, Geoff Evans, Julia Field, and Sharon Witherspoon. 1991. Understanding Political Change: The British Voter, 1964-1987. Oxford: Pergamon. 
Hetherington, Marc J., and Jonathan D. Weiler. 2009. Authoritarianism and Polarization in American Politics. New York: Cambridge University Press. https://doi .org/10.1017/ CB09780511802331

Hochschild, Arlie Russell. 2016. Strangers in Their Own Land: Anger and Mourning on the American Right. New York: The New Press.

Hout, Michael, Clem Brooks, and Jeff Manza. 1995. "The Democratic Class Struggle in the United States, 1948-1992." American Sociological Review 60(6):805-28. https : //doi .org/ $10.2307 / 2096428$

Inglehart, Ronald. 1977. The Silent Revolution: Changing Values and Political Styles among Western Publics. Princeton: Princeton University Press.

Inglehart, Ronald. 1997. Modernization and Postmodernization: Cultural, Economic, and Political Change in 43 Societies. Princeton: Princeton University Press.

Iyengar, Shanto, and Sean J. Westwood. 2015. "Fear and Loathing across Party Lines: New Evidence on Group Polarization." American Journal of Political Science 59(3):690-707. https://doi.org/10.1111/ajps.12152

Jackson, John E., and Ken Kollman. 2011. "Connecting Micro- and Macropartisanship." Political Analysis 19(4):503-18. https://doi.org/10.1093/pan/mpr030

Judis, John B. 2016. The Populist Explosion: How the Great Recession Transformed American and European Politics. New York: Columbia Global Reports.

Katz, Richard S. 1979. “The Dimensionality of Party Identification: Cross-National Perspectives." Comparative Politics 11(2):147-63. https://doi .org/10.2307/421753

Keele, Luke, and Jennifer Wolak. 2006. "Value Conflict and Volatility in Party Identification." British Journal of Political Science 36(4):671-90. https://doi.org/10.1017/ S0007123406000354

Keith, Bruce E., David B. Magleby, Candice J. Nelson, Elizabeth Orr, and Raymond E. Wolfinger. 1992. The Myth of the Independent Voter. Berkeley: University of California Press.

Knoke, David. 1972. "A Causal Model for the Political Party Preferences of American Men." American Sociological Review 37(6):679-89. https : //doi .org/10.2307/2093579

Knoke, David, and Michael Hout. 1974. "Social and Demographic Factors in American Political Party Affiliations, 1952-72." American Sociological Review 39(5):700-13. https : //doi.org/10.2307/2094315

Lazarsfeld, Paul Felix, Bernard Berelson, and Hazel Gaudet. [1944] 1948. The People's Choice: How the Voter Makes up His Mind in a Presidential Campaign. New York: Columbia University Press.

Levendusky, Matthew S. 2009. "The Microfoundations of Mass Polarization." Political Analysis 17(2):162-76. https://doi.org/10.1093/pan/mpp003

Lewis-Beck, Michael S., William G. Jacoby, Helmut Norpoth, and Herbert F. Weisberg. 2008. The American Voter Revisited. Ann Arbor: University of Michigan Press. https: //doi.org/10.3998/mpub.92266

MacKuen, Michael B., Robert S. Erikson, and James A. Stimson. 1989. "Macropartisanship." The American Political Science Review 83(4):1125-42. https : //doi .org/10. 2307/1961661

Manza, Jeff, and Clem Brooks. 1999. Social Cleavages and Political Change: Voter Alignments and US Party Coalitions. New York: Oxford University Press.

Meffert, Michael F., Helmut Norpoth, and Anirudh V. S. Ruhil. 2001. "Realignment and Macropartisanship." The American Political Science Review 95(4):953-62. 
Morgan, Stephen L. 2017. "A Coding of Social Class for the General Social Survey." GSS Methodological Report No. 125, National Opinion Research Center, Chicago, Illinois. https://doi.org/10.17605/OSF. IO/9NKRW

Morgan, Stephen L., and Minhyoung Kang. 2015. "A New Conservative Cold Front? Democrat and Republican Responsiveness to the Passage of the Affordable Care Act." Sociological Science 2:502-26. https : //doi .org/10.15195/v2 . a24

Miller, Patrick R., and Pamela Johnston Conover. 2015. "Red and Blue States of Mind: Partisan Hostility and Voting in the United States." Political Research Quarterly 68(2):22539. https://doi.org/10.1177/1065912915577208

Miller, Warren E. 1991. "Party Identification, Realignment, and Party Voting: Back to the Basics." The American Political Science Review 85(2):557-68. https : //doi .org/10 . 2307/ 1963175

Nieuwbeerta, Paul, Nan Dirk de Graaf, and Wout Ultee. 2000. "The Effects of Class Mobility on Class Voting in Post-War Western Industrialized Countries." European Sociological Review 16(4):327-48. https://doi.org/10.1093/esr/16.4.327

Silva, Jennifer. 2017. "We're Still Here: Pain and Politics in the Heart of America." Book Manuscript in Progress, Bucknell University, Lewisburg, Pennsylvania.

Smith, Tom W., Michael Davern, Jeremy Freese, and Michael Hout. 2017. General Social Surveys, 1972-2016, Cumulative Codebook. Chicago: NORC.

Sniderman, Paul M., and Edward H. Stiglitz. 2012. The Reputational Premium: A Theory of Party Identification and Policy Reasoning. Princeton: Princeton University Press.

Warren, Donald I. 1976. The Radical Center: Middle Americans and the Politics of Alienation. Notre Dame: University of Notre Dame Press.

Weakliem, David L. 1997. “Race Versus Class? Racial Composition and Class Voting, 19361992." Social Forces 75(3):939-56. https ://doi .org/10.2307/2580525

Weakliem, David L., and Julia Adams. 2011. "What Do We Mean by "Class Politics"?" Politics $\mathcal{E}$ Society 39(4):475-95. https://doi . org/10.1177/0032329211420047

Wright, Gerald C., and Nathaniel Birkhead. 2014. "The Macro Sort of the State Electorates." Political Research Quarterly 67(2):426-39. https ://doi .org/10.1177/1065912914522130

Acknowledgements: We thank Danny Schlozman for a helpful orienting discussion of these topics as well as Andy Cherlin, Mike Hout, Jennifer Silva, and Tom Smith for comments on the penultimate draft.

Stephen L. Morgan: Department of Sociology, Johns Hopkins University. E-mail: stephen.morgan@jhu.edu.

Jiwon Lee: Department of Sociology, Johns Hopkins University. E-mail: jiwonlee@jhu.edu. 